This item was submitted to Loughborough's Research Repository by the author.

Items in Figshare are protected by copyright, with all rights reserved, unless otherwise indicated.

\title{
Body mass index in mother and child dyads and its association with household size and parents' education in 2 urban settings of Yucatan, Mexico
}

\section{PLEASE CITE THE PUBLISHED VERSION}

https://doi.org/10.1177/0379572119842990

PUBLISHER

SAGE Publications () The Authors

VERSION

AM (Accepted Manuscript)

\section{LICENCE}

CC BY-NC-ND 4.0

\section{REPOSITORY RECORD}

Cauich-Vinas, Paulina, Hugo Azcorra, Luis Rodriguez, Sudip Datta Banik, Maria Ines Varela-Silva, and Federico Dickinson. 2019. "Body Mass Index in Mother and Child Dyads and Its Association with Household Size and Parents' Education in 2 Urban Settings of Yucatan, Mexico". Loughborough University. https://hdl.handle.net/2134/37754. 


\section{Food and Nutrition Bulletin}

\section{Body mass index in mother and child dyads and its association with household size and parents' education in two urban settings of Yucatan, Mexico}

\begin{tabular}{|c|c|}
\hline Journal: & Food and Nutrition Bulletin \\
\hline Manuscript ID & FNB-18-0163.R1 \\
\hline Manuscript Type: & Original Article \\
\hline $\begin{array}{r}\text { Date Submitted by the } \\
\text { Author: }\end{array}$ & $\mathrm{n} / \mathrm{a}$ \\
\hline Complete List of Authors: & $\begin{array}{l}\text { Cauich-Viñas, Paulina; Universidad Modelo } \\
\text { Azcorra, Hugo; Centro de Investigación y de Estudios Avanzados del } \\
\text { Instituto Politécnico Nacional , } \\
\text { Rodríguez, Luis; Universidad Autonoma de Yucatan, Facultad de } \\
\text { Matemáticas } \\
\text { DATTA BANIK, SUDIP; Centro de Investigación y de Estudios Avanzados } \\
\text { (Cinvestav) Del IPN, Unidad Mérida,, Human Ecology } \\
\text { Varela-Silva, Maria Ines; Loughborough University } \\
\text { DICKINSON, FEDERICO; Centro de Investigacion y de Estudios } \\
\text { Avanzados Unidad Merida, Department of Human Ecology }\end{array}$ \\
\hline Keywords: & Overweight, Poverty, Inequality, Maya, Mexico \\
\hline Abstract: & $\begin{array}{l}\text { Background: Overweight/obesity (OW/OB) coexists in mother-child } \\
\text { dyads. However, dearth of evidence on the factors associated with this } \\
\text { phenomenon calls for research. } \\
\text { Objective: To analyze the association of sociodemographic factors with } \\
\text { OW/OB in a sample of } 260 \text { Maya mother-child dyads from Yucatan, } \\
\text { Mexico. } \\
\text { Methods: During } 2011-2014 \text { we measured height and weight in children } \\
\text { and their mothers and calculated their body mass index (BMI). The } \\
\text { OW/OB cut-off points were defined, for mothers, as having a BMI } \\
\text { > } 25 \mathrm{~kg} / \mathrm{m} 2 \text { and, for children, as having a BMI-for-age }>2 \text { SD of the World } \\
\text { Health Organization references. Mother-child dyads were grouped } \\
\text { according to their BMI status: } 1 \text { ) normal weight mother and child, } 2 \text { ) } \\
\text { normal weight mother and OW/OB child, } 3 \text { ) OW/OB mother and normal } \\
\text { weight child, and } 4 \text { ) OW/OB mother and child. A multinomial logistic } \\
\text { regression model was used to analyze the interrelationships among BMI } \\
\text { status in mother-child dyads, household size and parental education. } \\
\text { Results: OW/OB coexisted in } 40 \% \text { of dyads. Compared to normal weight } \\
\text { dyads (1), each unit increase in household size and in years of maternal } \\
\text { education decreased the risks for the coexistence of OW/OB in mother- } \\
\text { child dyads (OR=0.72, } 95 \% \text { IC } 0.55-0.94, P=0.015 ; \text { OR=0.70, } 95 \% \text { IC } \\
\text { 0.52-0.94, P=0.019, respectively). Conversely, each year increase in } \\
\text { paternal education increased the risk for OW/OB in dyads (OR=1.47, } \\
95 \% \text { CI } 1.08-1.99, P=0.015) \text {. } \\
\text { Conclusions: Results suggest that household size and parental education } \\
\text { contribute to shape BMI-based nutritional status in this sample of }\end{array}$ \\
\hline
\end{tabular}


mother-child dyads. A higher level of maternal education acts as a protective factor against $O W / O B$ in mothers and children.

\section{SCHOLARONE \\ Manuscripts}




\title{
Body mass index in mother and child dyads and its association with household size and parents' education in two urban settings of Yucatan, Mexico
}

\author{
Paulina Cauich-Viñas, $\mathrm{MSc}^{1}$, Hugo Azcorra, $\mathrm{PhD}^{2}$, Luis Rodríguez, $\mathrm{PhD}^{3}$, Sudip Datta Banik, \\ $\mathrm{PhD}^{2}$, Maria Ines Varela-Silva, $\mathrm{PhD}^{4}$, Federico Dickinson, $\mathrm{PhD}^{2}$ \\ ${ }^{1}$ Universidad Modelo. Mérida, Yucatán, México \\ ${ }^{2}$ Centro de Investigación y de Estudios Avanzados del Instituto Politécnico Nacional. \\ Mérida, Yucatán, México. \\ ${ }^{3}$ Universidad Autónoma de Yucatán. \\ Mérida, Yucatán, México \\ ${ }^{4}$ Loughborough University. \\ Loughborough, United Kingdom. \\ Corresponding Author: \\ Hugo Azcorra \\ Centro de Investigación y de Estudios Avanzados del Instituto Politécnico Nacional. \\ Antigua carretera a Progreso km 6, C.P. 97310. Mérida, Yucatán, México. \\ E-mail: hugoazpe@,hotmail.com
}




\begin{abstract}
Background: Overweight/obesity $(\mathrm{OW} / \mathrm{OB})$ coexists in mother-child dyads. However, dearth of evidence on the factors associated with this phenomenon calls for research.

Objective: To analyze the association of sociodemographic factors with OW/OB in a sample of 260 Maya mother-child dyads from Yucatan, Mexico.

Methods: During 2011-2014 we measured height and weight in children and their mothers and calculated their body mass index (BMI). The OW/OB cut-off points were defined, for mothers, as having a BMI $>25 \mathrm{~kg} / \mathrm{m}^{2}$ and, for children, as having a BMI-for-age $>2 \mathrm{SD}$ of the World Health Organization references. Mother-child dyads were grouped according to their BMI status: 1) normal weight mother and child, 2) normal weight mother and OW/OB child, 3) OW/OB mother and normal weight child, and 4) OW/OB mother and child. A multinomial logistic regression model was used to analyze the interrelationships among BMI status in mother-child dyads, household size and parental education.
\end{abstract}

Results: OW/OB coexisted in $40 \%$ of dyads. Compared to normal weight dyads (1), each unit increase in household size and in years of maternal education decreased the risks for the coexistence of $\mathrm{OW} / \mathrm{OB}$ in mother-child dyads $(\mathrm{OR}=0.72,95 \%$ IC $0.55-0.94, \mathrm{P}=0.015 ; \mathrm{OR}=0.70$, 95\% IC 0.52-0.94, $\mathrm{P}=0.019$, respectively). Conversely, each year increase in paternal education increased the risk for $\mathrm{OW} / \mathrm{OB}$ in dyads $(\mathrm{OR}=1.47,95 \% \mathrm{CI} 1.08-1.99, \mathrm{P}=0.015)$.

Conclusions: Results suggest that household size and parental education contribute to shape BMI-based nutritional status in this sample of mother-child dyads. A higher level of maternal education acts as a protective factor against $\mathrm{OW} / \mathrm{OB}$ in mothers and children.

Keywords: overweight, poverty, inequality, Maya, Yucatan, Mexico 


\section{Introduction}

Globally, minority ethnic groups face higher risk for negative health and wellbeing outcomes than privileged groups. ${ }^{1,2}$ In Latin America and the Caribbean (LAC) countries, infant and maternal morbidity and mortality tend to be higher in minority ethnic groups due to several factors including discrimination, socioeconomic disadvantages, poor living conditions, and limited access to health services. ${ }^{2,3}$ Changes in the epidemiological profiles observed in LAC countries, where several minority ethnic groups reside, show clear increases in the prevalence of non-communicable diseases associated with obesity. ${ }^{4}$ Overweight and obesity $(\mathrm{OW} / \mathrm{OB})$ are chronic health conditions that carry high economic burden for individuals, families and communities. ${ }^{5}$ It is expected that these costs will be greater in minority ethnic groups due to their higher levels of material poverty and limited access to social security coverage.

Mexico has the largest number of inhabitants belonging to any indigenous groups in LAC countries. $^{3}$ The Maya represents the second largest ethnic group in Mexico ${ }^{6}$ and the Yucatan Peninsula of Mexico is the home of around 787,500 Maya people who reside in both urban and rural areas. ${ }^{7}$ Historically, the classical Maya had been widely recognized and valued by their significant advances in mathematics, astronomy, architecture and agricultural achievements. ${ }^{8}$ However, most of the living Maya nowadays face poverty and deprivation, and do not reap any benefit from their heritage. Most of the Maya population from Yucatan is integrated into a global economy of labour and consumption, while a small proportion of them depends on the traditional agricultural systems for subsistence. ${ }^{9}$

Available studies on nutritional status of urban Maya population from Yucatan show very high rates of $\mathrm{OW} / \mathrm{OB}$ in children and adult women. ${ }^{10,11}$ Several economic and political factors, including lack of economic support for agricultural activities in rural settings and the imposition 
of government policies relating to the national and global economy have urged a large number of Maya people to opt for very low paid jobs in urban centres like Merida, the capital city of Yucatan. ${ }^{12}$ This process has profoundly influenced food consumption and physical activity patterns among the Maya, increasing their susceptibility to OW/OB and other chronic diseases. ${ }^{13,14}$

Overnutrition can be studied at individual, mother-child pairs, familial and population levels. Mothers and their children are in closer contact and share more time and food environments than other members of the family and, therefore, similarities in body weight status are expected among them..$^{15}$ The study of mother-child dyads as a unit of analysis provides a useful scenario to investigate the influence of living conditions and of intergenerational effects on health and nutritional aspects of some of the most vulnerable members of minority groups.

The combination of BMI and weight outcomes, when analysing in mother-child dyads, can be seen in relation to different correlates that vary in terms of their social, economic, biological and health related issues. The coexistence of $\mathrm{OW} / \mathrm{OB}$ represents the scenario with social, economic and health costs for families and population. So far, these different outcomes in combinations have not been studied in depth. Many studies have analysed the impact of the dual burden of malnutrition at household level, in which maternal OW/OB coexists with childhood stunting. ${ }^{16,17,18}$ This is a familial phenotype that is frequently seen in low-and-middle income countries that are undergoing nutrition transition. However, OW/OB in mother-child dyads usually means that the nutrition transition has been experienced and phenotypes of these populations resemble the phenomenon observed in high-imcome countries where the epidemic of OW/OB has been prevalent.

In this background, we aim to analyse the association of sociodemographic factors, namely household size and parental education, with the presence or absence of concomitant 
OW/OB in a sample of 260 Maya mother-child dyads residing in the cities of Merida and Motul in Yucatan, Mexico.

\section{Methods}

Dataset used in the present study was a part of a research project on the influence of socioeconomic and intergenerational factors on growth and nutritional status of 6-to-8 year old Maya children from the cities of Merida and Motul in Yucatan, Mexico. The research was a cross-sectional in nature that aimed to analyse how living conditions experienced by mothers and maternal grandmothers during their childhood had associations with growth and body composition characteristics of children in younger generation. Inclusion criteria was based on 1) age of children (6.00-8.99 years), 2) the mother was the biological mother of child and 3) each member of the triad (maternal grandmother, mother, and child) had to have at least one maternal Maya surname. In Mexico, people use both patronymic and matronymic surnames that can be considered as a genetic proxy and a means to identify ethnic affinity. ${ }^{19,20,21}$ We focused on 6-to 8year-old children because during this stage skeletal growth rate tends to be stable or decelerating, and there are few skeletal maturation differences between boys and girls. ${ }^{22}$ In this study, we focus on anthropometric characteristics of mothers and their children in the background of selected household sociodemographic factors. The sample consisted of 260 mother-child dyads from Merida $\left(\mathrm{n}_{1}=180\right)$ and Motul $\left(\mathrm{n}_{2}=80\right)$.

Merida, located in the north-central region of the Yucatan Peninsula, is the capital city of Yucatan state. In 2015, Merida was inhabited by 892,363 people, 11\% of them being Maya speakers. The presence of Maya people in Merida has long history; however, during the last decades the city has become an increasingly important destination for rural-to-urban Maya migrants. Maya people residing in Merida work mostly in construction, manufacturing, domestic, 
commercial, transport and other services as low-wage employees. ${ }^{12}$ Motul is located around 30 km away from Merida in the north-central region of the state. In 2016, Motul was inhabited by 36,097 people, $25 \%$ of them being Maya speakers. The higher proportion of Maya people living in this city in comparison with Merida is partially explained by the presence of haciendas (treasury of the landholders) in Motul neighbourhood, where Maya people worked as labourers in the production of sisal fibre (Agave flouricoides) in $19^{\text {th }}$ and $20^{\text {th }}$ centuries. The current labour market in Motul primarily consists of small-scale agriculture and livestock, commerce, manufacturing operations (maquiladoras) and tourism.

\section{Data collection}

From September 2011 to January 2014 we conducted a cross-sectional study in which we measured height and weight of children and their mothers, and calculated their body mass index (BMI=weight $[\mathrm{kg}] /$ height $\left[\mathrm{m}^{2}\right]$ ). During the duration of the project, three sessions of anthropometric standardization were implemented in which only $<5 \%$ of inter-observer technical error of measurement was acceptable. Children were measured in schools between 7 and 10 a.m., before playtime, and mothers during household visits. In each case, the time elapsed between the measurement of the child and his/her mother was not longer than five days. Majority of the mothers were present in the schools during their children's measurement. The anthropometric measures were taken by trained personnel following standardised procedures ${ }^{23} \mathrm{Height}(\mathrm{cm})$ and BMI $\left(\mathrm{kg} / \mathrm{m}^{2}\right)$ of children were transformed into z-score values (height-for-age and BMI-for-age) using the growth reference data published by Frisancho. ${ }^{24}$ The World Health Organization (WHO) growth references were selected for this study.

Mother-child dyads from Merida were recruited from 47 primary schools located in several regions of the city. In order to allow for greater socioeconomic variability in the sample, 
we randomly selected 10 participants from each school. Dyads from Motul were recruited from 12 primary schools of the city.

Overweight/obesity cut-off points $(\mathrm{OW} / \mathrm{OB})$ were defined, for the mothers, as having $\mathrm{BMI}>25 \mathrm{~kg} / \mathrm{m}^{2}$ and, for the children, as having a BMI-for-age above $2 \mathrm{SD}$ of the WHO references. ${ }^{25}$ Mother-child dyads were grouped into four categories according to OW/OB and normal weight conditions: 1) normal weight mother - normal weight child, 2) normal weight mother - OW/OB child, 3) OW/OB mother - normal weight child and, 4) OW/OB mother OW/OB child.

During household visits, we used a questionnaire to record data of household socioeconomic characteristics. For the purposes of this study, the variables of interest were: household size and parental education. The socioeconomic conditions in Maya families improves as the household size decreases and this indicator can be related to the distribution and accessibility of resources. Household size was defined as the total number of people living permanently at house. In this sample, household size ranged from 2 to 13 members. Parental education has shown to be positively associated with child growth and nutritional status ${ }^{26,27}$, and evidence suggest that effects of parents' education effect are larger in poor socioeconomic settings and in populations with high burden of malnutrition ${ }^{27}$, such as the Maya. We included education of the mother and father since both have shown to be important for offspring health. ${ }^{28}$ Parents' education levels were recorded in years. For descriptive purposes, data were grouped into three categories: 1) None, 2) Primary school, 3) Junior high school, 4) Senior high school and 5) Professional degrees (university and technical education).

\section{Statistical analyses}

Student's t-test was used to find significant differences of mean values between two groups. Chi-square tests were used to compare the proportions of OW/OB between groups. A 
logistic regression model was also used to estimate the odds of being OW/OB in children given the presence or absence of $\mathrm{OW} / \mathrm{OB}$ in mothers. A multinomial regression model was used to analyse the interrelationships between sociodemographic factors and BMI-based nutritional status in mother-child dyads. Household size and parent's education (years) were used as predictors. Maternal and children's age (both in years) and sex $(1=$ boys, $2=$ girls $)$ were used as covariates in the model. Since a small number of dyads fall in the category of normal weight mother OW/OB child $(\mathrm{n}=9)$ the outcome variable was restricted in this analysis into three categories: 1$)$ normal weight mother - normal weight child, 2) OW/OB mother - normal weight child and, 3) OW/OB mother - OW/OB child. The category of normal weight mother - normal weight child was used as the reference in the model. We report the odds ratio (OR), standard error, $95 \%$ confidence interval and p-value for each predictor. Statistical analyses were done using the Stata/IC 11.1 for Windows statistical package. Significance level in all analyses was $\alpha=0.05$.

\section{Ethical concerns}

This research project was approved by the Bioethics Committee for the Study of Human Beings of the Centre for Research and Advanced Studies of the National Polytechnic Institute of Mexico and the Loughborough University Ethics Advisory Group (R11-P133). Mothers signed the consent forms for themselves and also on behalf of their children. All children provided us with verbal assent while measured. For ethical reasons, adult women were measured only by women of the research team.

\section{Results}

We found no significant differences in anthropometric and sociodemographic data between participants from Merida and Motul. Therefore, results are based on the pooled sample from the two cities. 


\section{Sociodemographic characteristics}

Participants belong to relatively large families $($ mean $=5.10, \mathrm{SD}=1.88)$ with low levels of parental education being 33\% of below primary school (Table 1). No significant differences were identified neither in years of education nor in the proportions of education levels between mothers and fathers.

\section{[PLEASE INSERT TABLE 1 HERE]}

\section{Nutritional status of mother-child dyads}

On average, children's BMI-for-age z-score values were one standard deviation above the mean of the WHO references. The mean value for mother's BMI was close to the upper limit of overweight category according to the WHO criteria (Table 2). A large proportion of children $(43.90 \%)$ and mothers $(85.80 \%)$ met the criteria for OW/OB. No significant difference was observed in the proportions of OW/OB children by sex (boys $=45.45 \%$ vs girls $=42.19 \%, \mathrm{X}_{(1)}^{2}=$ $0.282, \mathrm{P}>0.05)$. No participant in this study met the criteria for being underweight. Regarding the combinations of nutritional status of mothers and children, the highest percentage of dyads (46\%) was found in the category of $\mathrm{OW} / \mathrm{OB}$ mother and normal weight child, followed by $\mathrm{OW} / \mathrm{OB}$ mother and child (40\%), normal weight dyads (10\%) and normal weight mother and OW/OB child (4\%). These frequencies did not vary significantly according to children's sex $\left(\mathrm{X}^{2}{ }_{(2)}=\right.$ $0.544, \mathrm{P}>0.05)$.

We observed that higher proportions of OW/OB children were clustered in the group of OW/OB mothers (47\% vs 25\% respectively). Logistic regression analysis showed that being an OW/OB mother, more than doubled the odds of children to be classified as $\mathrm{OW} / \mathrm{OB}(\mathrm{OR}=2.65$, 95\% CI 1.16-5.80).

[PLEASE INSERT TABLE 2 HERE] 


\section{Factors associated with nutritional status of mother-child dyads}

Multinomial regression analysis (Table 3) showed that, compared to the normal weight dyads, each unit increase in household size, and in years of maternal education, decreased the odds for the presence of $\mathrm{OW} / \mathrm{OB}$ in mothers and children $(\mathrm{OR}=0.72,95 \%$ IC $0.55-0.94, \mathrm{P}=$ 0.015; OR $=0.70,95 \%$ IC $0.52-0.94, p=0.019)$. This implies children and mothers are less likely to be OW/OB if they live in bigger houses and if the mothers report higher educational qualifications. Conversely, each year increase in father's education also increased the odds for the presence of $\mathrm{OW} / \mathrm{OB}$ in members of both generations $(\mathrm{OR}=1.47,95 \% \mathrm{CI} 1.08-1.99, \mathrm{P}=0.015)$. No predictor included in the model was found to be significantly associated with the category of OW/OB mother and normal weight child.

\section{[PLEASE INSERT TABLE 3 HERE]}

\section{Discussion}

In summary, our results show that excess body weight coexists in $40 \%$ of mother-child dyads. Our analysis shows that household size and years of maternal education were negatively associated with the risk for OW/OB in mother-child dyads and conversely, fathers' education increased the risk for the presence of OW/OB in mothers and children.

The $43.9 \%$ of children in the sample met the criteria for high BMI-for-age, which is greater compared to national prevalence $(34.6 \%)$ and similar to that found in Yucatan state (45.2\%), according to the 2012 Mexican National Survey of Health and Nutrition. ${ }^{29}$ The prevalence of $\mathrm{OW} / \mathrm{OB}$ in the mothers was $12.8 \%$ and $4 \%$ greater than national and Yucatan figures $($ National $=73 \%$, Yucatan $=82 \%)$, respectively. Previous studies from Yucatan reported that children and youth with Maya ancestry or individuals belonging to disadvantaged socioeconomic groups tend show poorer growth status, including increased risk for excess body 
weight. ${ }^{30,31}$ In this sense, Ulijaszek proposes that societies characterized by strong economic and social gradations tend to produce an unequal manifestations of diseases. Ethnic groups that occupy the lowest rank in terms of wealth and societal position are especially impacted upon. ${ }^{32}$

Despite the recognition of the importance of mother-child dyads as a useful approach to obtain valuable information that would allow to improve health status in populations, very limited data about the prevalence of the coexistence of excess body weight in mother-child pairs is available. In their study on geographic relationships of nutritional status as measured by BMI among Kenyan mothers and children (3-to-5 years of age), Pawloski and collaborators ${ }^{33}$ found that the most frequent category was normal weight mother - normal weight child (49.3\%), followed by OW/OB mother - normal weight child (14.8\%). Only 5.7\% Kenyan dyads, mostly clustered in urban areas of the country, showed the coexistence of excess body weight, a prevalence substantially lower than that found in our Maya sample.

In general, it is expected that the coexistence of excess body weight in mothers and offspring increases if the frequency of $\mathrm{OW} / \mathrm{OB}$ rises separately in adult women and children. Despite this, no other study to the best of our knowledge has analysed factors associated with OW/OB in mother-child pairs. Therefore, results of this study contribute to the limited discussion about the influence of intra-household level factors on nutritional status of Maya families from Yucatan, Mexico. We found that households with fewer members showed an increased risk for having OW/OB in mothers and their children. As reported earlier ${ }^{34}$, living conditions of urban Maya families improve as household size decreases, which allows us to expect a negative association between household size and the risk of excess body weight in dyads that might be explained by a larger amount of foods and type of care to each member as the household size decreases. This finding is consistent with previous studies done in poor socioeconomic setings. ${ }^{35,36}$ Our results also show that mother-child dyads are less likely to be OW/OB if the 
mothers have more years of education and more likely if the fathers report higher educational qualification. It has been proposed that parental education acts as an indicator of children's health through two interrelated lanes. First, higher education may cause changes in parental values, which is related to household income and allocation of resources towards children's and parents' health awareness. Second, more years of schooling may improve cognitive skills, facilitating increased household income and health awareness. ${ }^{37}$ Most of the mothers in the studied sample are not engaged in regular salaried jobs and are responsible of the dayli household chores and children care. Therefore, we may suggest that maternal education acts through decisions related to food selection and preparation inside the household. In this regard, evidence suggest that the association of dietary practices between parents and children tend to be stronger in mother and child dyads than fathers. ${ }^{38}$ We suggest that father's education acts through household income and higher paternal income may cause a greater access to overall amount of food. These results are consistent with McLaren's review ${ }^{39}$ in the sense that in countries with medium and low Human Development Index (a measure of national development based on people and economic growth), obesity is positively associated with higher levels of education among men, but negatively in women. In the case of children, available studies suggest that inequalities experienced by parents, but particularly by mothers, can shape rates of OW/OB among their offspring. ${ }^{40,41}$ Therefore, it is possible that the coexistence of excess body weight observed in $40 \%$ of dyads are explained by a complex interaction of factors including a relatively greater capacity for food purchasing, the selection of products with high caloric content and the distribution of resources among a small number of members in the household.

Nutritional status of adult women and children of the present study may have several implications not only for population but also for health personel. We think the coexistence of excess body weight in mother-child dyads may tend to normalize the presence of unhealthy 
weights at household and community levels and therefore, undersestimate their detrimental consequences of obesity on health and well being. Normalization of OW/OB may prevent successful actions of practitioners and researchers when they try to make behavioural changes in diet and physical activity or focus on obesity prevention.

We presume that current nutritional status of the Maya might be also explained by factors at macro-level. Briefly, the Maya exemplify sociodemographic changes recently experienced by other ethnic groups. Until the end of nineteenth century, a large proportion of Maya people resided in rural areas in the context of the hacienda system and in communities as small-scale farmers. ${ }^{42}$ Traditional Maya diet and their living conditions presumed a high energy expenditure due to long and exhausting working hours. Due to several factors such as the deterioration of soil fertility, lack of government support for agriculture and the fall of the agro-industrial system of sisal, a considerable number of Maya people migrated to the main cities of the Yucatan. ${ }^{12,43}$ The urban dynamics transformed the sociodemographic and cultural characteristics of the Maya. National policies related to birth control have contributed to a substantial reduction in the size of families. The labour dynamics based on salaried work has modestly increased the income of families and therefore, their purchasing capacity. In this context, the urban Maya has been exposed to a food supply characterized by a diverse range of products of low cost, but nutritionally poor where local elements of the traditional diet were replaced by the commercially produced foods. ${ }^{44}$

Finally, our results show the urgent need for action at different levels to improve the health conditions of the Maya population. As a fundamental principle, it is essential that living conditions of the Maya improve and that needs active policy measures designed by the government, such as regular access to education, especially for girls. 


\section{Limitations}

Limitations of our research include the lack of information that could help us to better understand the studied phenomenon. First, we lack data about participants' diet and physical activity levels, factors that could influence individual prevalences of OW/OB and thereby the combinations of these conditions in mother-child dyads. Second, we also lack data about other relevant characteristics of the parents and household that could explain the coexistence of OW/OB among dyads, including household income, food expenditure, and maternal perceptions about their own body shape and that of their children.

In conclusion, excess body weight is a widespread condition in this sample of Maya mothers and their children and parental years of schooling and household size contribute to shape the coexistence of this condition in mother-child dyads. The results call for an urgent need for interventions at different levels in the Maya population.

\section{Acknowledgments}

This study was supported by National Science and Technology Council of Mexico (Consejo Nacional de Ciencia y Tecnología, contract grant number: 168047). The authors thank those who assisted with the field work: Graciela Valentín Sánchez and Adriana Vázquez-Vázquez. Additional fieldwork assistance was provided by Frida Gutiérrez and Samantha Sánchez. We appreciate the cooperation of mothers and their children who agreed to participate in the study.

\section{Author contributions}

This study derives substantially from the Master's thesis of Paulina Cauich-Viñas under the supervision of Hugo Azcorra. Paulina Viñas-Cauich and Hugo Azcorra formulated the research question and wrote the first draft of the manuscript. Hugo Azcorra and Luis Rodríguez analysed the data. Federico Dickinson, Sudip Datta Banik and Maria Ines Varela-Silva contributed to the 
creative process of this paper by providing scientific content and intellectual additions on the subsequent drafts of the manuscript.

\section{Conflict of interest}

The authors declare that they have no conflicts of interest with the contents of this article.

\section{Funding}

The data reported here were collected as part of a project funded by the National Science and Technology Council of Mexico; Consejo Nacional de Ciencia y Tecnología de México (Conacyt). Contract grant number: 168047.

\section{References}

1. Stephens C, Nettleton C, Porter J, Willis R, Clark S. Indigenous peoples' health-why are they behind everyone, everywhere? Lancet. 2005;366(9479):10-13.

2. Gracey M, King M. Indigenous health part 1: determinants and disease patterns. Lancet. $2009 ; 374(4): 65-75$.

3. Montenegro R, Stephens C. Indigenous health in Latin America and the Caribbean. Lancet. 2006;367(9225):1859-1869.

4. De Maio F. Understanding chronic non-communicable diseases in Latin America: towards and equity-based research agenda. Glob Health. 2011;7(36).

5. Runge CF. Economic consequences of the obese. Diabetes. 2007;56(11):2668-2672.

6. Comisión Nacional para el Desarrollo de los Pueblos Indígenas. Indicadores socioeconómicos de los pueblos indígenas de México. https://www.gob.mx/cms/uploads/attachment/file/239923/04-estimaciones-nacionales-porentidad-federativa.pdf Accessed February 15, 2019 
7. Instituto Nacional de Estadística, Geografía e Informática. Hablantes de lengua indígena en México. http://cuentame.inegi.org.mx/poblacion/lindigena.aspx?tema=P\#uno Accessed February 16, 2019.

8. Thompson JES. The civilization of the Mayas. Chicago: Field Museum of Natural History; 1973.

9. Ramírez Carrillo LA. Pobres pero globales. Desarrollo y desigualdad social en el sureste de México. México, DF: Universidad Autónoma de Yucatán - Miguel Ángel Porrúa; 2015.

10. Azcorra H, Varela-Silva MI, Rodríguez L, Bogin B, Dickinson F. Nutritional status of Maya children, their mothers, and their grandmothers residing in the city of Merida, Mexico: revisiting the leg-length hypothesis. Am J Hum Biol. 2013;25(5):659-665.

11. Méndez N, Barrera-Pérez M, Palma-Solís M, Zavala-Castro J, Dickinson F, Azcorra H, et. al. Ethnicity and income impact on BMI and stature of school children living in urban southern Mexico. J Biosoc Sci. 2016;48(2):143-157.

12. Lizama Quijano JJ. Del pueblo a la urbe. El perfil maya de la blanca Mérida. México, DF: Centro de Investigaciones y de Estudios Superiores en Antropología Social; 2012.

13. Bogin B, Azcorra H, Wilson HJ, Vázquez-Vázquez A, Ávila ML, Castillo-Burguete MT, et al. Globalization and children's diets: The case of Maya of Mexico and Central America. Anthropol Rev. 2014;77(1):11-32.

14. Azcorra H, Wilson H, Bogin B, Varela-Silva MI, Vázquez-Vázquez A, Dickinson F. Dietetic characteristics of a sample of Mayan dual burden households in Merida, Yucatan, Mexico. ALAN. 2014;63(3):209-217.

15. Tzioumis E, Adair LS. Childhood dual burden of under- and over-nutrition in low- and middle-income countries: A critical review. Food Nutr Bull. 2014;35(2):230-243. 
16. Doak CM, Adair LS, Bentley M, Monteiro C, Popkin BM. The dual burden household and the nutrition transition paradox. Int J Obes. 2005;29:129-136.

17. Jehn M, Brewis A. Paradoxical malnutrition in mother-child pairs: untangling the phenomenon of over- and under-nutrition in underdeveloped economies. Econ Hum Biol. $2009 ; 7: 28-35$.

18. Khor GL, Sharif ZM. Dual forms of malnutrition in the same households in Malaysia--a case study among Malay rural households. Asia Pac J Clin Nutr. 2003;12:427-437.

19. Chakraborty R, Barton SA, Ferrel RE. Ethnicity determination by names among the Aymara of Chile and Bolivia. Hum Biol. 1989;61:159-177.

20. Colantonio S, Lasker GW, Kaplan BA, Fuster V.Use of surname models in human population biology: A review of recent developments. Hum Biol. 2003;75:785-807.

21. Relethford JH. 1995. The use of surnames in the study of human variation and plasticity. In: Mascie-Taylor GCN and Bogin B, editors. Human Variability and Plasticity p.146158.

22. Bogin B. Patterns of Human Growth. Cambridge: Cambridge University Press. 1999: 455.

23. Lohman T, Roche A, Martorell R. Anthropometric standardization reference manual. Abridged Edition. Champaign: Human Kinetics Books; 1988.

24. Frisancho R. Anthropometric standards: An interactive nutritional reference of body size and body composition for children and adults. Ann Arbor: The University of Michigan Press; 2008

25. De Onis M, Lobstein T. Defining obesity risk status in the general childhood population: Which cut-offs should we use? Int J Pediatr Obes. 2010;5(6):458-460.

26. Moestue H, Huttly S. Adult education and child nutrition: the role of family and community. J Epidemiol \& Community Health. 2008;62(2):153-159. 
27. Alderman H, Headey D D. How important is parental education for child nutrition? .World Dev. 2017;94:448-464.

28. Vollmer S, Bommer C,Krishna A, Harttgen K, Subramanian SV.The association of parental education with childhood undernutrition in low- and middle-income countries: comparing the role of paternal and maternal education. Int J Epidemiol. 2017;46:312-323

29. Instituto Nacional de Salud Pública. INSP. Encuesta Nacional de Salud y Nutrición 2012. Resultados por entidad federativa, Yucatán. Cuernavaca, México. 2013. http://www.encuestas.insp.mx Accessed July 15, 2015.

30. Vázquez-Vázquez A, Azcorra H, Falfán I, Argáez J, Kantun D, Dickinson F. Effects of Maya ancestry and environmental variables on knee height and body proportionality in growing individuals in Merida, Yucatan. Am J Hum Biol. 2013;25(5):586-593.

31. Mendez N, The Late Mario Barrera-Pérez, Palma-Solis M, Zavala-Castro J, Dickinson F, Azcorra H, Prelip M. Ethnicity and income impact on BMI and stature of school children living in urban southern Mexico. J Biosoc Sci. 2015;48(2):143-157.

32. Ulijaszek S. Models of obesity. From ecology to complexity in science and policy. Cambridge, UK: Cambridge University Press; 2017.

33. Pawloski L, Curtin M, Gewa C, Attaway D. Maternal-child overweight/obesity and undernutrition in Kenya: a geographic analysis.Public Health Nutr. 2012;15(11):21402147.

34. Azcorra H, Rodriguez L, Datta Banik S, Bogin B, Dickinson F, Varela-Silva M I. Living conditions and change in age menarche in adult Maya mothers and daughter from Yucatan, Mexico. Am J Hum Biol. 2018;30(2). 
35. Gewa C. Childhood overweight and obesity among Kenyan pre-school children: association with maternal and early child nutritional factors. Public Health Nutr. 2009; 13(4):496-503.

36. Fernald LC, Neufeld LM. Overweight with concurrent stunting in very young children from rural Mexico: prevalence and associated factors. Eur J Clin Nutr. 2007;61:623-632.

37. Glewwe P. Why does mother's schooling raise child health in developing countries? Evidence from Morocco. J Hum Resour. 1999;34:124-59.

38. Oliveria SA, Ellison RC, Moore LL et al. Parent-child relationships in nutrient intake: the Framingham Children's Study. Am J Clin Nutr. 1992;56:593-598

39. McLaren L. Socioeconomic status and obesity. Epidemiol Rev. 2007;29(1):29-48.

40. Gibson LY, Byrne SM, Davis EA, Blair E, Jacoby P, Zubrick SR. The role of family and maternal factors in childhood obesity. Med J Aust. 2007;186(11):591-595.

41. Rooney BL, Mathiason MA, Schauberger CW. Predictors of obesity in childhood, adolescence, and adulthood in a birth cohort. Matern Child Health J. 2011;15(8):11661175.

42. Farris N. La sociedad maya bajo el dominio colonial. México, DF: Instituto Nacional de Antropología e Historia; 2005.

43. Bracamonte P. Una deuda histórica. Ensayo sobre las causas de pobreza secular de los mayas yucatecos. México, DF: CIESAS-Porrúa-ICY; 2007.

44. Leatherman TL, Hoke MK, Goodman AH. Local nutrition in global contexts: critical biocultural perspectives on the nutrition transition in Mexico. In: Zuckerman MK, Martin DL, ed. New Directions in Biocultural Anthropology. Hoboken: Wiley Blackwel; 2016 : 49-65. 
Table 1. Sociodemographic characteristics of studied households.

\begin{tabular}{lr}
\hline \multicolumn{1}{c}{ Variable } & Mean (SD) $/ \%$ \\
\hline Family size (\# of members) & $5.10(1.88)$ \\
\hline Maternal age (years) & $32.99(5.53)$ \\
\hline Maternal education & $4.96(2.18)$ \\
\hline Years of education & 12 \\
\hline Levels of education & 22 \\
\hline None & 43 \\
\hline Primary School & 13 \\
\hline Junior High School & 10 \\
\hline Senior High School & \\
\hline University and Technical career & \\
\hline Paternal education & 5.00 \\
\hline Years of education & $2.09)$ \\
\hline Levels of education & 44 \\
\hline None & 17 \\
\hline Primary School & 6 \\
\hline Junior High School & \\
\hline Senior High School & \\
\hline University and Technical career & \\
\hline
\end{tabular}

Abbreviations: SD, standard deviation. 
Table 2. Descriptive statistic of anthropometric and derived variables of mothers and children.

\begin{tabular}{|c|c|c|c|c|}
\hline \multirow[t]{2}{*}{ Variable } & \multicolumn{3}{|c|}{ Children } & \multirow[t]{2}{*}{ Mothers } \\
\hline & Total & Girls & Boys & \\
\hline & Mean $(\mathrm{SD}) / \%$ & Mean $(\mathrm{SD}) / \%$ & Mean (SD) $/ \%$ & Mean $(\mathrm{SD}) / \%$ \\
\hline Age (years) & $7.54(0.83)$ & $7.51(0.80)$ & $7.57(0.86)$ & $32.99(5.53)$ \\
\hline Height $(\mathrm{cm})$ & $120.53(7.07)$ & $120.17(7.19)$ & $120.89(6.95)$ & $147.80(4.95)$ \\
\hline Height-for-age (z-score) & $-0.64(0.93)$ & $-0.60(0.96)$ & $-0.68(0.91)$ & - \\
\hline Weight $(\mathrm{kg})$ & $26.44(6.97)$ & $26.05(6.91)$ & $26.82(7.02)$ & $65.10(11.60)$ \\
\hline $\mathrm{BMI}\left(\mathrm{kg} / \mathrm{m}^{2}\right)$ & $17.95(3.13)$ & $17.80(3.06)$ & $18.10(3.21)$ & $29.74(4.73)$ \\
\hline BMI-for-age (z-score) & $1.02(1.25)$ & $0.90(1.17)$ & $1.15(1.25)$ & - \\
\hline $\begin{array}{l}\text { Exceeded BMI }(\%) \\
(\mathrm{OW} / \mathrm{OB})^{\mathrm{a}}\end{array}$ & 43.90 & 42.20 & 45.50 & 85.80 \\
\hline $\begin{array}{l}\text { Abbreviations: SD, stan } \\
\text { overweight/obesity. } \\
{ }^{a} \text { Overweight } / \text { obesity cut } \\
>25 \mathrm{~kg} / \mathrm{m}^{2} \text { and, for the cl } \\
\text { Organization references } \\
\text { (adults: BMI }<18 \mathrm{~kg} / \mathrm{m}^{2}\end{array}$ & $\begin{array}{l}\text { d deviation; BI } \\
\text { f points were d } \\
\text { lren, as having } \\
\text { one mother or } \\
\text { iildren }<-2 \text { SD i }\end{array}$ & $\begin{array}{l}\text {, body mass ind } \\
\text { ined, for the mo } \\
\text { BMI-for-age }>2 \\
\text { ild met the crite } \\
\text { BMI-for-age). }\end{array}$ & $\begin{array}{l}\mathrm{x} ; \mathrm{OW} / \mathrm{OB}, \\
\text { ers, as having a } \\
\mathrm{D} \text { of the World } \\
\text { a for low BMI }\end{array}$ & $\begin{array}{l}\text { BMI } \\
\text { Health } \\
\text { underweight }\end{array}$ \\
\hline
\end{tabular}


Table 3. Multinomial regression model for categories of BMI status in mother-child dyads. ${ }^{\mathrm{a}}$

\begin{tabular}{|c|c|c|c|}
\hline Category & OR & p-value & $95 \% \mathrm{CI}$ \\
\hline \multicolumn{4}{|c|}{ Normal weight mother - Normal weight child $(n=27)$ Base outcome $=1$} \\
\hline \multicolumn{4}{|c|}{ Overweight/Obese mother - Normal weight child $(n=119)$} \\
\hline Maternal age (years) & 1.08 & 0.111 & $0.98-1.20$ \\
\hline Child age (years) & 0.98 & 0.952 & $0.54-1.78$ \\
\hline Child sex (girls) & 0.80 & 0.651 & $0.31-2.09$ \\
\hline Family size & 0.88 & 0.267 & $0.70-1.10$ \\
\hline Maternal education (years) & 0.82 & 0.168 & $0.62-1.09$ \\
\hline Paternal education (years) & 1.20 & 0.233 & $0.89-1.62$ \\
\hline \multicolumn{4}{|c|}{ Overweight/Obese mother - Overweight/Obese child $(n=105)$} \\
\hline Maternal age (years) & 1.07 & 0.173 & $0.97-1.19$ \\
\hline Child age (years) & 1.31 & 0.398 & $0.70-2.44$ \\
\hline Child sex (girls) & 0.80 & 0.657 & $0.29-2.17$ \\
\hline Family size & 0.72 & 0.015 & $0.55-0.94$ \\
\hline Maternal education (years) & 0.70 & 0.019 & $0.52-0.94$ \\
\hline Paternal education (years) & 1.47 & 0.015 & $1.08-1.99$ \\
\hline
\end{tabular}

Abbreviations: OR, odds ratio; CI, confidence interval.

aThe category Normal weight mother - OW/OB child was not included given the small number of cases $(n=9)$. 